ISSN 1991- 8690

الترقيم الدولي . 1991 - 199

website: http://jsci.utq.edu.iq

Email: utjsci@utq.edu.iq

\title{
Variation of band edge, optical constant and dispersion parameters of CdS thin films due to disorder induced by fast neutron irradintion
}

\author{
Hashim M. Jabbar \\ Hussam S. Al-Selman \\ Dpt. Of Physics - College of Science- Basrah University- Iraq
}

\begin{abstract}
CdS thin films were prepared by thermal evaporation method, optical constant of the deposited films were obtained from the analysis of the expirmental recorded transmittance spectral data over a wavelength range of (200-900)nm. The value of refractive index of unradiated and radiated samples are determined from these spectra using Swanepoel's model. It has been found that the dispersion data obey single-oscillator relation of the Wemple-DiDomenico model from which the dispersion parameters were determined the third order optical susceptibility $\chi^{(3)}$ of unradiated and irradiated $\mathrm{CdS}$ thin film were also determined using these spectra. and the optical absorption at the fundamental absorption edge was discussed. Direct optical energy gap $E_{g}^{o p t}$ and Urbach (localized states) energy were also calculated for all unradiated and irradiated CdS thin films.
\end{abstract}

\section{Introduction}

Thin films nowadays occupy a prominent space in basic research and solid state technology. The use of thin film semiconductors has attracted much interest in an expanding variety of applications in various electronic and optoelectronic devices due to their low production costs. Cadmium sulphide CdS is one of the most promising II-VI compound materials due to its wide range of applications in various optoelectronic [1], piezo-electronic [2] and semiconducting devices. Thin films of $\mathrm{CdS}$ are of considerable interest for their efficient use in fabrication of solar cells $[3,4]$.

Cadmium sulphide which belongs to II-VI group is the most widely used material for CdS/CdTe and $\mathrm{CdS} / \mathrm{Cu} 2 \mathrm{~S}$ heterojunction solar cells, because of the fact that $\mathrm{CdS}$ has intermediate energy band gap, reasonabl conversion efficiency, stability and low cost [5,6].In semiconducting materials under irradiation, a chain of reactions, in which oxygen and moisture from invironment may be incorporated, starts with rapid electronic phenomena, this is followed by the generation of reactive, short-lived intermediate compounds and complex mixture of chemical products. The main result of ionization is breaking of chemical bonds and the creation of new ones, which causes change in optical and electrical properties and lead to long-lived forms of physical breakdown. [7]. The importance of studying the optical properties of a material is offered by the ability of this technique to provide informations regarding the fundamental gap, electronic transition, traping levels and localized states [8].The aim of this work is to study the effect of fast 
neutron radiation on the band edge, localized states, optical constant, and dispersion parameters of CdS thin films.

\section{Experimental}

The pure CdS thin films were prepared on glass substrates at room temperature by thermal evaporation method at vacuum $10^{-5}$ Torr.

The crystalline structure of the films were investigated by standard X-ray diffraction (XRD) technique, using CUK $\alpha$ radiation $\left(\lambda=1.54 \mathrm{~A}{ }^{\circ}\right)$. More detailed information about the preparation procedure and XRD pattern for pure CdS thin film can be found in the work of H.S. Al-Selman [9].

$\mathrm{CdS}$ sample were irradiated with fast neutrons that emitted from Am-Be (in Contact). The yield of the neutron source was $1.1 \times 10^{7} \mathrm{n} / \mathrm{s}$ the neutron fluence of Am-Be source was found to be $(3.9 \pm 0.78) \times 10^{9} \mathrm{n} / \mathrm{cm}^{2}$ for each day of a irradiation and the mean energy of its emitted neutrons was 4.5 MeV[10]. The source was supplied by Radio-chemical Ltd, Amersham, England.

The optical absorbance (A) and Transmittance (T) of the unradiated and irradiated samples were measured at room temperature using (Helios- $\alpha$ spectronic

\section{$\underline{\text { Results and discussion }}$}

Transmission spectrum is used to calculate the refractive index using the envelope method proposed by Swanepoel ,The refractive index (n) has been obtained using the following expressions[11].

$$
\begin{aligned}
& n=\left[M+\left(M^{2}-S^{2}\right)^{1 / 2}\right]^{1 / 2} \\
& M=\frac{25}{T_{m}}=\frac{\left(S^{2}+1\right)}{2} \\
& M=25 \frac{T_{M}-T_{m}}{T_{M} T_{m}}+\frac{\left(S^{2}+1\right)}{2}-(1) \\
& \text { region. } \\
& S=\frac{1}{T_{S}}+\sqrt{\frac{1}{T_{S}^{2}}-1}
\end{aligned}
$$

$T_{M}$ and $T_{m}$ are the values of maximum and minimum transmission values at a particular wavelength, "S" is the refractive index of the substrate, $T_{\mathrm{s}}$ is the transmission of the substrate Refractive index can be estimated by extrapolating envelops corresponding to $T_{M}$ and $T_{m}$. As the thickness of the film is uniform, interference give rise to the spectrum as shown in Fig (1). 


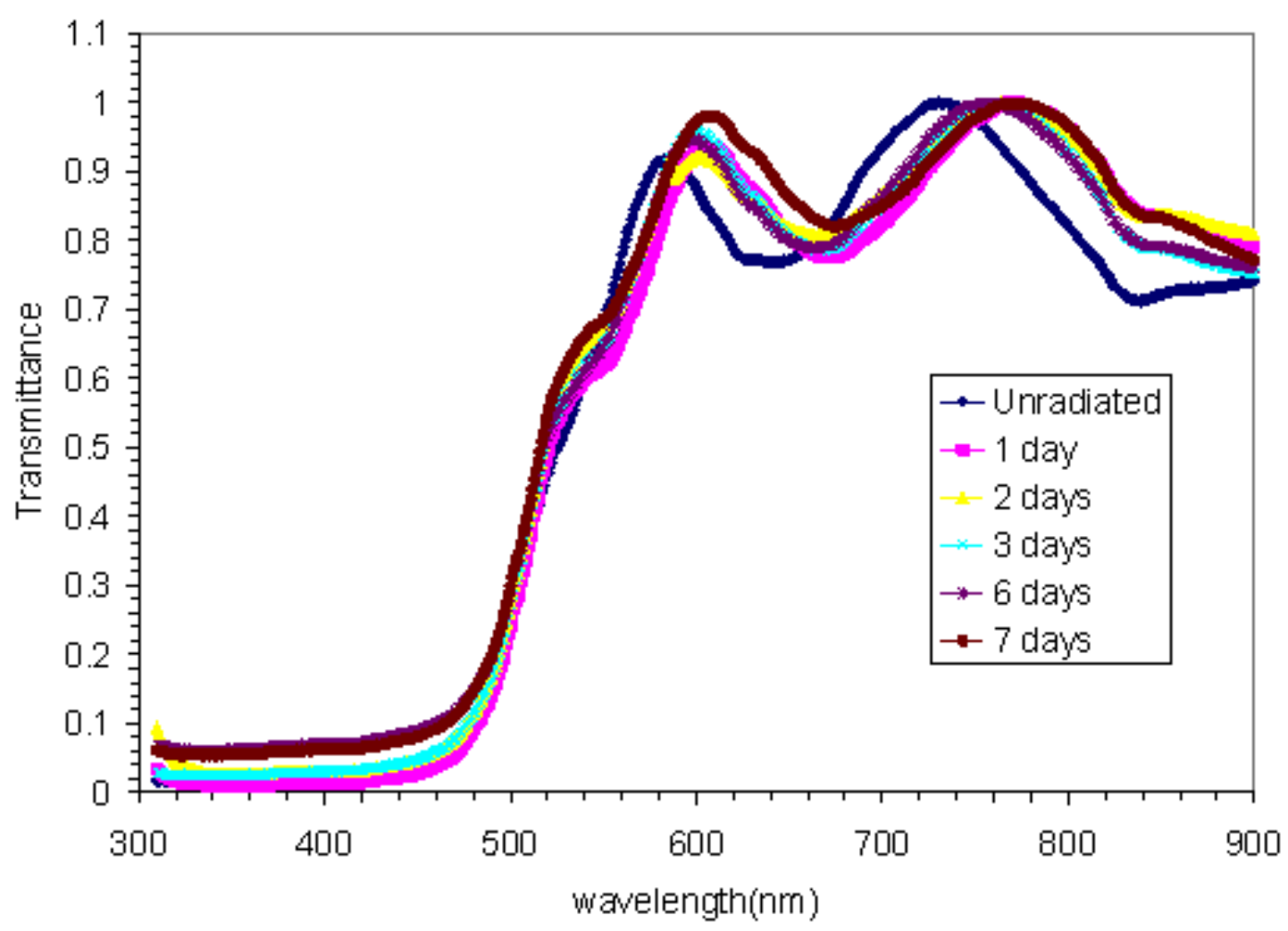

Fig1.Variation of transmittance with wavelength for unradiated and irradiatd CdS thin films

The variation of refractive index with the wavelength is shown in Fig(2) for unradiated and irradiated CdS thin films.

We studied the spectral dispersion of the refractive index for unradiated and irradiated CdS samples. The dispersion spectrum of the refractive index was fitted using the Cauchy formula [12]

$n=A+\frac{B}{\lambda^{2}}$

where A and B are the Cauchy's parameters.

The calculated values for A and B are given in table I.

Refractive index found to decrease with increasing irradiation time. This may be due to the change of the lattice structure. 


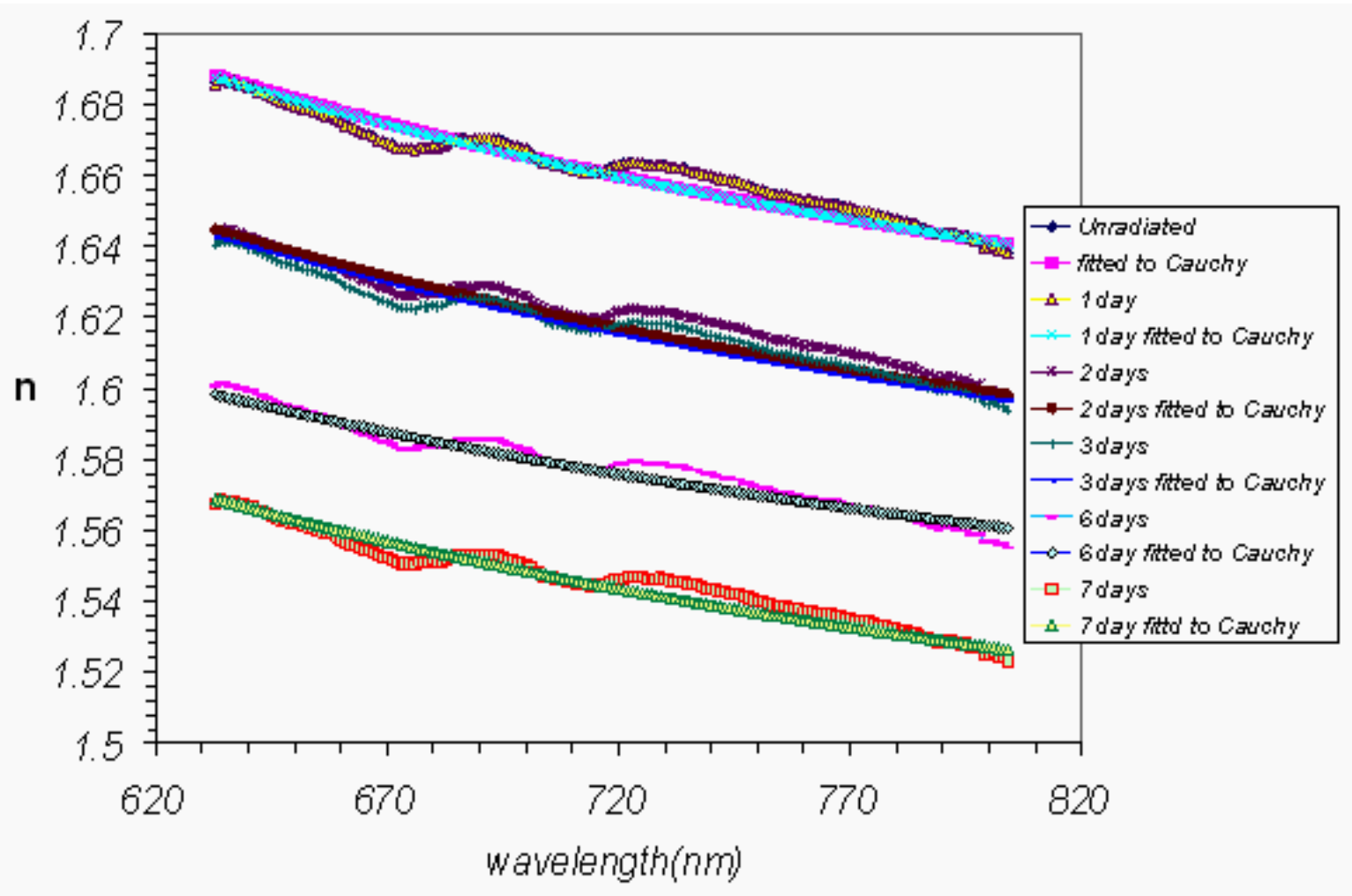

Fig.2 Variation of refractive index with wavelength for unradiated and irradiated $\mathrm{CdS}$ thin films

Table I: Cauchy Parameters for unradiated and irradiated pure CdS thin films

\begin{tabular}{|c|c|c|c|}
\hline \multicolumn{2}{|c|}{ Irradiation } & \multirow{2}{*}{ A } & \multirow{2}{*}{ B (nm) ${ }^{2}$} \\
\cline { 1 - 2 } Dosage (day) & Fluence $\frac{\text { neutron }}{\mathrm{cm}^{2}} \times 10^{\circ}$ & & \\
\hline 0 & 0 & 1.5643 & 49403 \\
\hline 1 & 3.9 & 1.5630 & 50190 \\
\hline 2 & 7.8 & 1.5225 & 39614 \\
\hline 3 & 11.7 & 1.5209 & 48936 \\
\hline 6 & 23.4 & 1.4994 & 48786 \\
\hline 7 & 27.3 & 1.4571 & 44800 \\
\hline
\end{tabular}


Based on single-oscillator model, the Wimple-DiDomenico is a semi-empirical dispersion relation for determining the refractive index at photon energies below the interband absorption edge as a variety of materials, it is given by[12].

$$
\mathrm{n}^{2}-1=\mathrm{E}_{\mathrm{o}} \mathrm{E}_{\mathrm{d}} /\left\{\mathrm{E}_{\mathrm{o}}^{2}-(\mathrm{h} v)^{2}\right\}
$$

Where $h v$ is the photon energy, $E_{o}$ is the energy of the effective dispersion oscillator also called average energy gap, $E_{d}$ is the oscillator strength or the dispersion energy, which measures the average strength of the interband optical transitins. Plotting $\left(n^{2}-1\right)^{-1}$ against $(h v)^{2}$ allows us to determine the oscillator parameters by fitting a straight line to the points. Fig (3) shows the plot of $\left(n^{2}-1\right)^{-1}$ versus $(h v)^{2}$. The value of $E_{o}$ and $E_{d}$ can be directly determined from the slop $\left(\mathrm{E}_{\mathrm{o}} \mathrm{E}_{\mathrm{d}}\right)^{-1}$ and the intercept on vertical axis $\left(\mathrm{E}_{\mathrm{o}} / \mathrm{E}_{\mathrm{d}}\right)$. The calculated values of $\mathrm{E}_{\mathrm{o}}$ and $\mathrm{E}_{\mathrm{d}}$ are given in table II.



The values of static refractive indices $\mathrm{n}(0)$ for unradiated and irradiated Cds thin films were calculated by extrapolating the Wemple-DiDomenico dispersion to $(h v \rightarrow 0)$ 
Table II : Single oscillator parameters calculated by WDD approximation for unradiated and irradiated pure CdS thin films

\begin{tabular}{|c|c|c|c|c|c|c|}
\hline \multicolumn{2}{|c|}{ Irradiation } & \multirow[b]{2}{*}{$\mathrm{E}_{0}(\mathrm{ev})$} & \multirow[b]{2}{*}{$\mathrm{E}_{\mathrm{d}}(\mathrm{ev})$} & \multirow[b]{2}{*}{$E_{8}=\frac{E_{0}}{1.6}(\mathrm{ev})$} & \multirow[b]{2}{*}{$n(0)$} & \multirow[b]{2}{*}{$\epsilon_{\infty}$} \\
\hline $\begin{array}{l}\text { Time } \\
\text { (day) }\end{array}$ & Fluence $\frac{\text { neutron }}{\mathrm{cm}^{2}}$ & & & & & \\
\hline 0 & 0 & 3.85 & 5.5 & 2.406 & 2.47 & 6.10 \\
\hline 1 & 3.9 & 3.84 & 5.4 & 2.40 & 2.428 & 5.89 \\
\hline 2 & 7.8 & 3.81 & 4.76 & 2.38 & 2.25 & 5.06 \\
\hline 3 & 11.7 & 3.78 & 4.74 & 3.36 & 2.23 & 4.99 \\
\hline 6 & 23.4 & 3.74 & 4.70 & 2.33 & 2.219 & 4.92 \\
\hline 7 & 27.3 & 3.62 & 4.067 & 2.26 & 2.20 & 4.86 \\
\hline
\end{tabular}

According to Wagner [13] the Miller rule is very convenient for visible and nonlinear and near infrared frequencies, which equalize the third order nonlinear polarizability parameter, $\chi^{(3)}$, the so-colled nonlinear optical susceptibility, and the linear optical susceptibility, $\chi^{(1)}$, through the equation[13].

$$
\chi^{(3)}=\mathrm{A}\left(\chi^{(1)}\right)^{4}=\mathrm{A}\left[\mathrm{E}_{0} \mathrm{E}_{\mathrm{d}} / 4 \pi\left(\mathrm{E}_{0}^{2}-(\mathrm{hv})^{2}\right]^{4}=\mathrm{A} /(4 \pi)^{4}\left(\mathrm{n}^{2}-1\right)^{4}\right.
$$

where $\mathrm{A}=1.7 \times 10^{-10}$. Fig(4) shows the plot of $\chi^{(3)}$ with hv

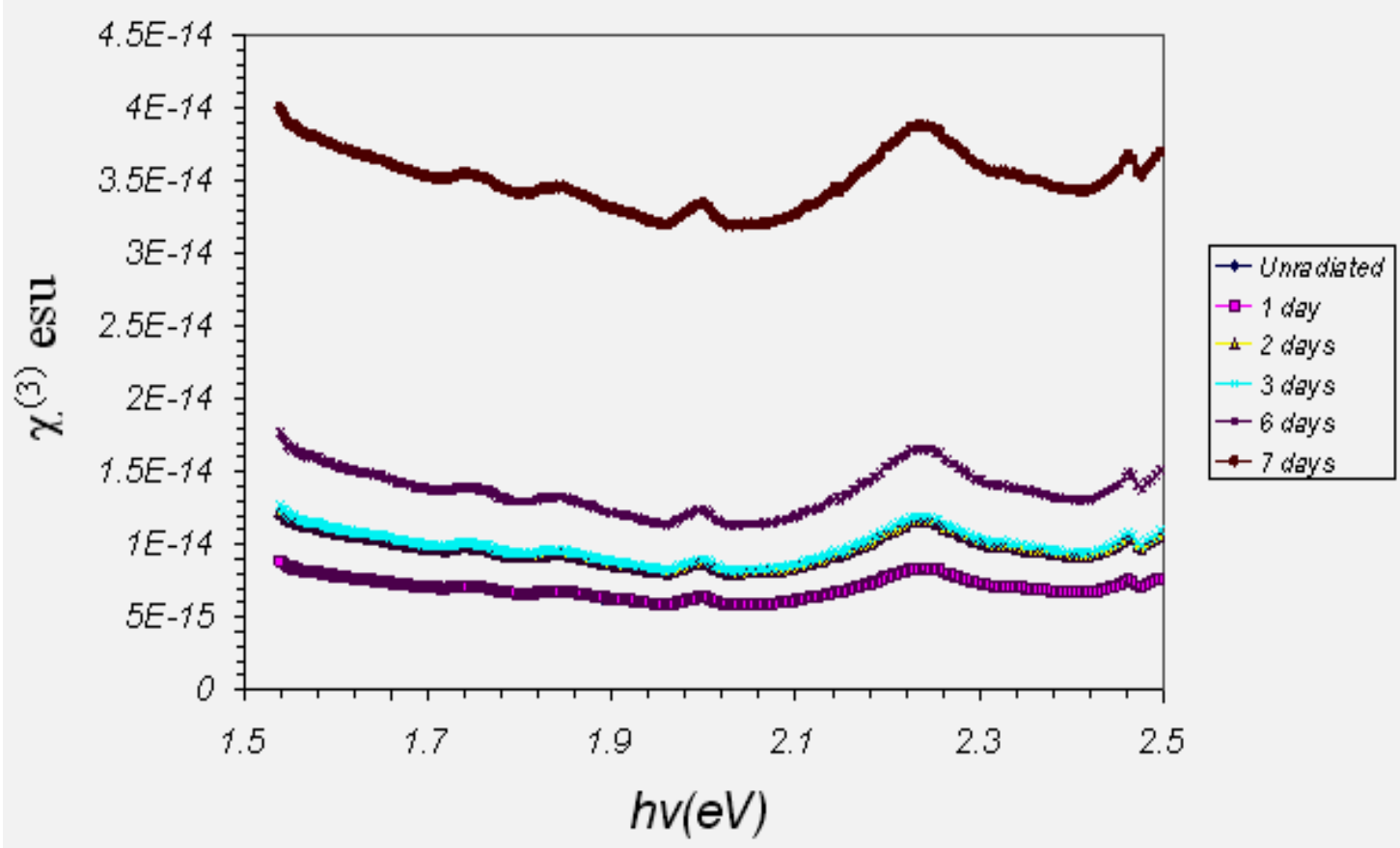

Fig.4 Variation of third order nonlinear optical susceptibility with photon energy For unradiated and irradiated $\mathrm{CdS}$ thin films

At the absorption edge, the absorption coefficient can be calculated using the expression [14]. 
$\alpha=\frac{1}{d} \ln \left(\frac{1}{T}\right)$

where $d$ is the thickness of the sample

In the high absorption region from which the optical band gap is determined, the absorption is characterized by Tauc's relation [1].

$$
\alpha h v=\beta\left(h v-E_{g}^{o p t}\right)^{r}
$$

Where $h v, E_{g}^{o p t}$ and $\beta$ denotes the photon energy, the optical gap and band tailing parameter respectively. In the above equation; $r=1 / 2$ were used for direct allowed transition. Figs (5) shows the plot between $(\alpha h v)^{2} \operatorname{vis}(h v)$ for calculation of optical band gap $E_{g}^{o p t}$. The optical gap determined by the intercept of the extrapolations to zero absorption with he photon energy axis[ $\left.(\alpha h v)^{2} \rightarrow 0\right]$ Tauc extrapolation [14].

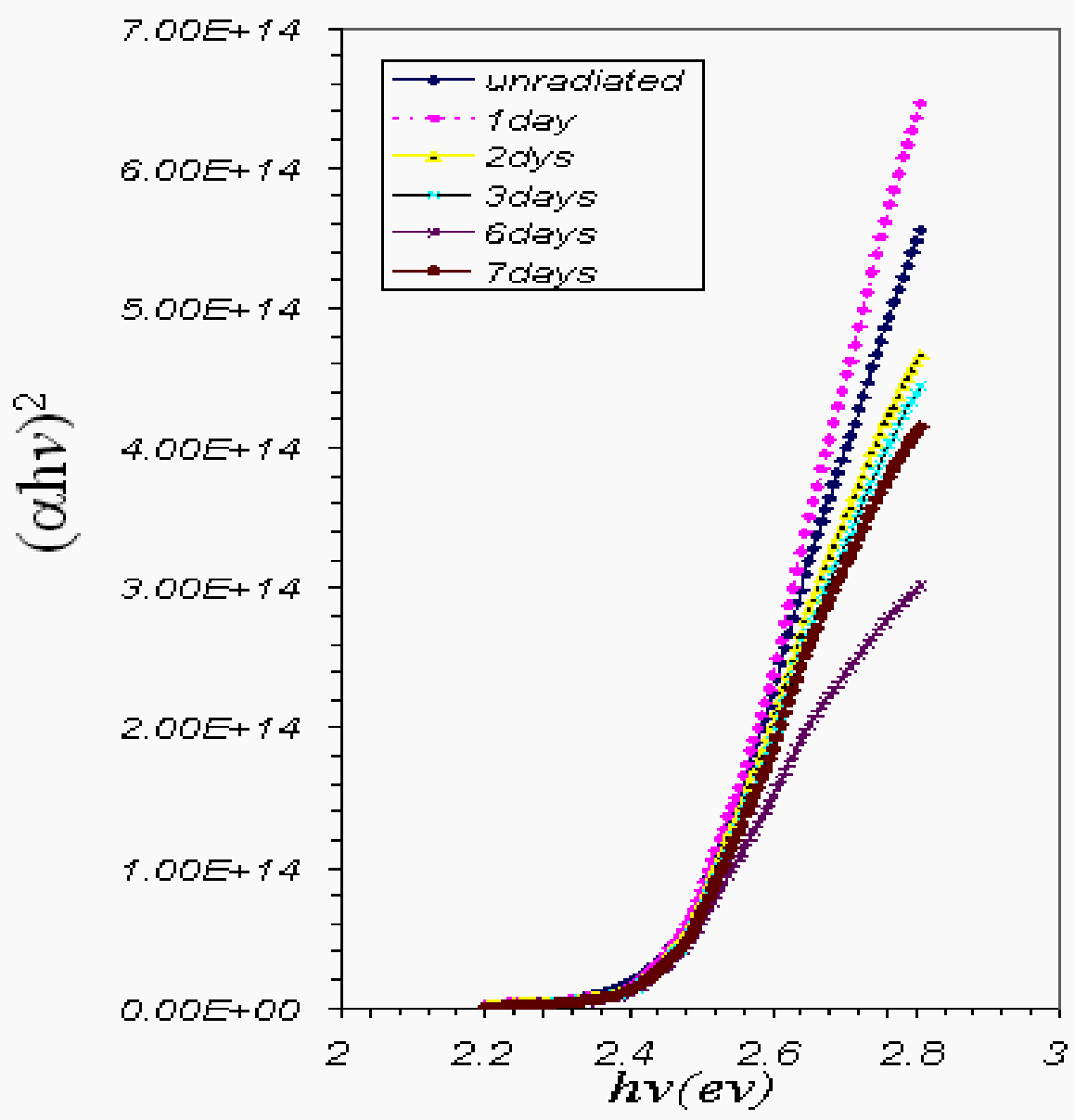

\section{Fig.5 Variation of $(\alpha h v)^{2}$ with $h v$ for unradiated and irradiated CdS thin}

Urbach [14] proposed an empirical rule between the absorption coefficient $\alpha(h v)$ and the photon energy $(h v)$ known as Urbach tail:- 
$\alpha(h v)=\alpha_{o} \exp \left[h v / E_{u}\right]$

where $E_{u}$ represents the width of the band tails (Urbach tail states).

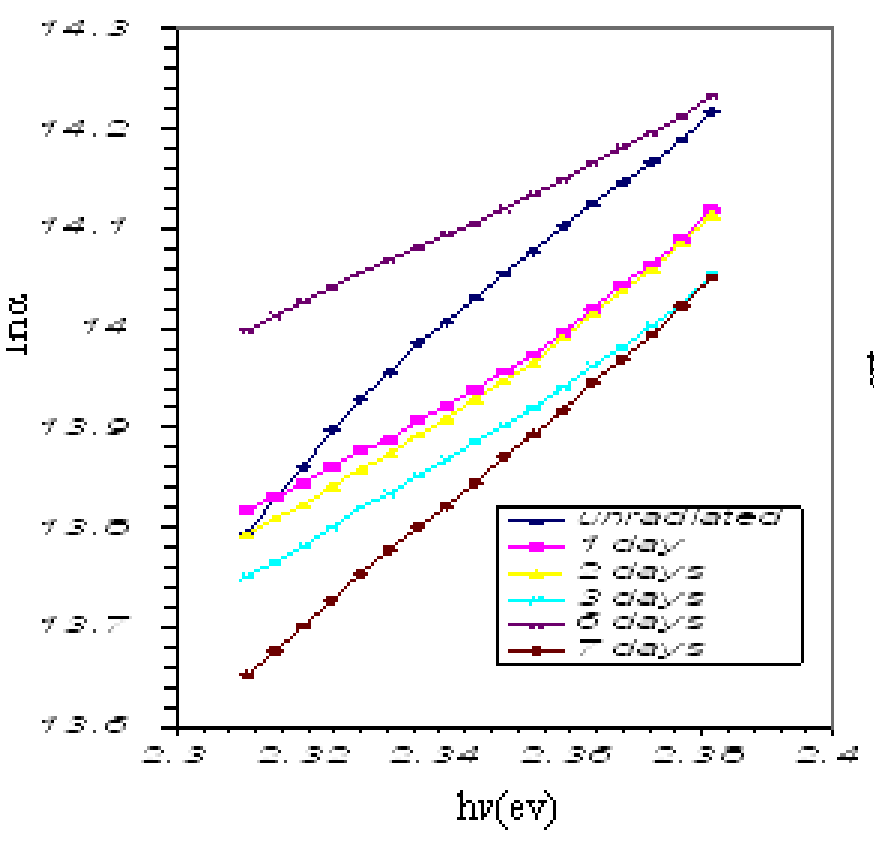

Fig 6. In $\alpha$ vis $\mathrm{h} v$ for unradiated and irradiated CdS thin films

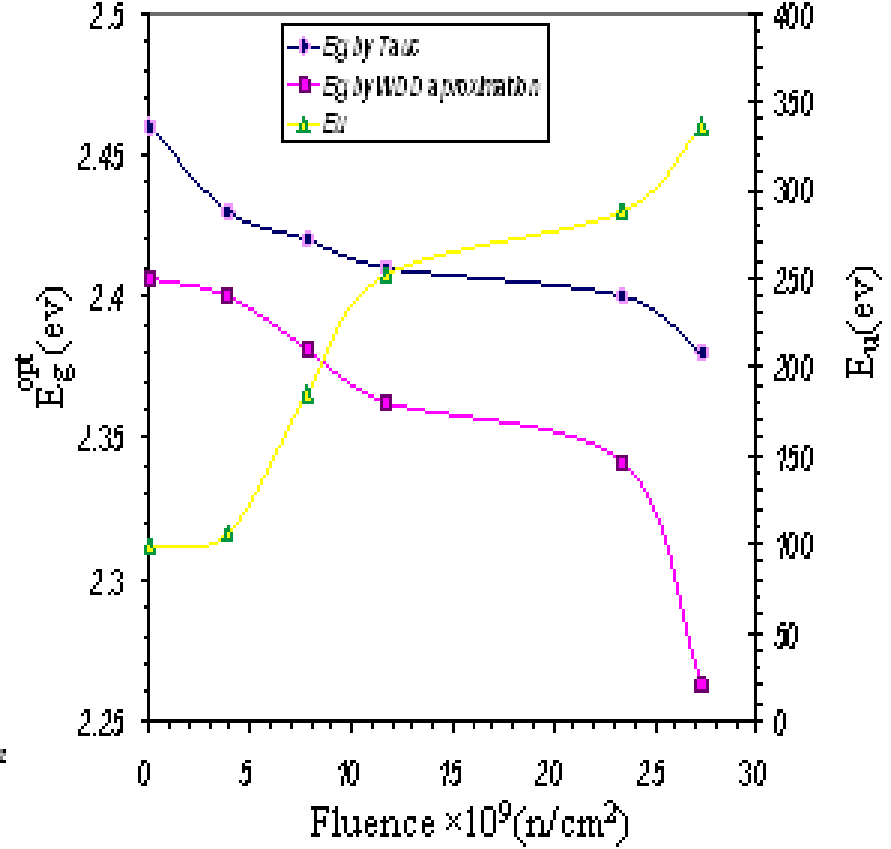

Fig7. $E_{g}^{o p t}$ of Tauc and $E_{g}^{o p t}$ of WDD approximation and width of the tail $E_{u}$ as a function of fluence

A large variety of insulators and crystalline semiconductors exhibits similar tails in the optical-absorption coefficients. It generally believed that disorder plays a significant role in developing Urbach band tails.[14]

\begin{tabular}{|c|c|c|c|}
\hline \multicolumn{2}{|c|}{ Irradiation } & \multirow{2}{*}{$E^{2}(\mathrm{ev})$} & \multirow{2}{*}{$\mathrm{E}_{\mathbf{u}}(\mathrm{mev})$} \\
\cline { 1 - 2 } Dosage (day) & Fluence $\frac{\text { neutron }}{\mathrm{cm}^{2}} \times 10^{\circ}$ & & \\
\hline $\mathbf{0}$ & $\mathbf{0}$ & $\mathbf{2 . 4 6}$ & $\mathbf{9 9}$ \\
\hline $\mathbf{1}$ & $\mathbf{3 . 9}$ & $\mathbf{2 . 4 3}$ & $\mathbf{1 0 6}$ \\
\hline $\mathbf{2}$ & $\mathbf{7 . 8}$ & $\mathbf{2 . 4 2}$ & $\mathbf{1 8 5}$ \\
\hline $\mathbf{3}$ & $\mathbf{1 1 . 7}$ & $\mathbf{2 . 4 1}$ & $\mathbf{2 5 2}$ \\
\hline $\mathbf{6}$ & $\mathbf{2 3 A}$ & $\mathbf{2 . 4 0}$ & $\mathbf{2 8 8}$ \\
\hline 7 & $\mathbf{2 7 3}$ & $\mathbf{2 . 3 8}$ & $\mathbf{3 3 6}$ \\
\hline
\end{tabular}

Table III : Optical gap $E_{g}^{o p t}$ and the width of the band tail for unradiated and irradiated pure $\mathrm{CdS}$ thin films

Some theoretical and experimental studies have demonstrated that an optical band gap energy $E_{g}$ in semiconductors can be expressed as [15] 
$E_{g}=E_{x}-\beta E_{u}$

Some theoretical studies assert that both Tauc gap and Urbach energy are influenced from structural disorder, and that $\mathrm{E}_{\mathrm{x}}$ represents the band gap in disorder-free materials.

Defects and a large density of broken bonds forming grain boundries and leading to a discontinuous structure which does not influence the detailed shape of the band structure. It causes a considerable blurring of the edges of the conduction and the valance bands and gives rise to distribution of deep localized levels (tail states) in the forbidden gap $[16,17]$. The presence of high concentration of localized states in the band structure is responsible for low value of the optical energy gap $E_{g}^{o p t}[18,19]$.

\section{Conclusions}

Pure CdS thin films were fabricated using thermal evaporation method.,optical properties of unradiated and fast neutron irradiated CdS samples were studied using transmittance spectra,refractive indices were calculated using swanepoel's model of transmittance spectra, refractive index decreases with an increasing in neutron irradiation time (fluence),dispersion of refractive index was successfully fitted with Cauchy, and good agreement between the models is observed,dispersion energy and oscillation strength values were determined using Wemple-

DiDomenico approximation, $E_{o}, E_{d} n(o)$ and $\in_{\infty}$ falls with an increasing in neutron irradiation time (fluence), $3^{\text {rd }}$ order optical susceptibility $\chi^{(3)}$ was calculated for unradiated and irradiated Cds samples, $\chi^{(3)}$ falls with an increasing fluence,optical energy gap $E_{g}^{o p t}$ falls while $E_{u}$ rises with an increasing in neutron irradiation time (fluence), the change of the optical parameter values is an indication that the effect of fast neutron irradiation are able to systematically modify the optical properties of the pure CdS thin film.

\section{References}

[1] C. S. Tepantlan, V. Arreola, "Structural Optical and Electrical Properties of Cds thin films obtained by spray pyroloysis",Revista Mexicana De Fisica Vol. 54, No.2, pp.112-117, April 2008.

[2] D Patidar, R Sharma and N Jian "Optical Properties of Cds Sintered film" Bul Matter Sci, Vol 29, No.1 pp.21-24, Feb.2006.

[3] K.Sachin,L. Kumar,"Dependence of Eg on deposition parameters of CdSe",Chalcgenide Letter ,Vol5,No.4,pp73-78,2008

[4] R. Devi", P Purkayash, P.K Kalita and B Sharma,"Synthesis and characterization of CdS thin films in PVA matrix", Bull matter Sci, Vol 30, No.2, pp.123-128,April 2007

[5] A. Ashour "physical properties of spray pyrolysed CdS thin films",Turk Jr Phys, Vol27,pp551$558, \mathrm{Feb} 2003$

[6] H.Lee,W.C.Song,J.S.Yi "Growth and properties of the $\mathrm{Cd}_{1-\mathrm{x}} \mathrm{Zn}_{\mathrm{x}} \mathrm{S}$ thin films for solar cell applications" Thin Solid films,pp349-353,2003

[7] Holmes-Siedle, A-G., and L.Adms "Handbook of Radiation effect" New York, Oxford university press-1993.

[8] Heavens, O.S., Optical properties of thin film, New York, Dover, 1991.

[9] H.S. Al-Selman,"Effect of Al on the structure and optical properties of CdS thin film" Journal Basrah Researches (Sci), To be published.

[10] Ammar A. Al-Sa'ad,"Measurements of high fluences of neutron that registered on on CR-39 plastic detector using optical density technique" Journal Basrah Researches (Sci), Vol.34, No.4, 15 August 2008.

[11]P. Sharma, V. Sharma, S.C. Katyal, "variation of optical constants in $\mathrm{Ge}_{10} \mathrm{Se}_{60} \mathrm{Te}_{30}$ thin film",chalcogenide letters, Vol.3, No.10, p73-79 October 2006

[12]T. Singh,"Optical properties of condensed matter and applications",John Wiley and sons ,Itd 2006 
[13]M. Hemissi, H. Amar dija-Adnani: "Optical and Structural Properties of Titanium Oxide Thin Films Prepared by Sol-gel Method", Digest Jr. of nano materials, Vol2, No.4, p.299-305, December 2007.

[14]R. Schyoder,"Characterization of organic and inorganic using advanced spectroscopic method", Thesis, Verginia Institute ,December 2001

[15]Keji Tanaka, Shin-ichi Nakayama "Where is the mobilties edge in amorphous semiconductor?" Jr of optoelectronics and advanced materials, Vol.2, No.1, pp. 5-11 March 2000.

[16]V. Ferrando, I Pallecchi, C. Tarantini, D. Marre, M. Putti "Systematic Study of disorder induced by netron irradiation in MgB2 thin films"-LAMIA-CNR-INFM and university di Genova 16146 Genova-Italy 2008.

[17] Kishimoto, N, et al.," Radiation -Induced conductivity of doped Silicon in response to photon, proton and neutron irradiation", Jr of neuclear materials, Vol.283-287, No.2, PP.907-911, 2000.

[18]Jilly, R.J.D," Principles of applications of chemical defects", U.K.: Stanely Thornes, 1998.

[19]S.Chaudhuri and S.Biswas ,"Solid State Comunications",Vol53,No3,p273 ,1985

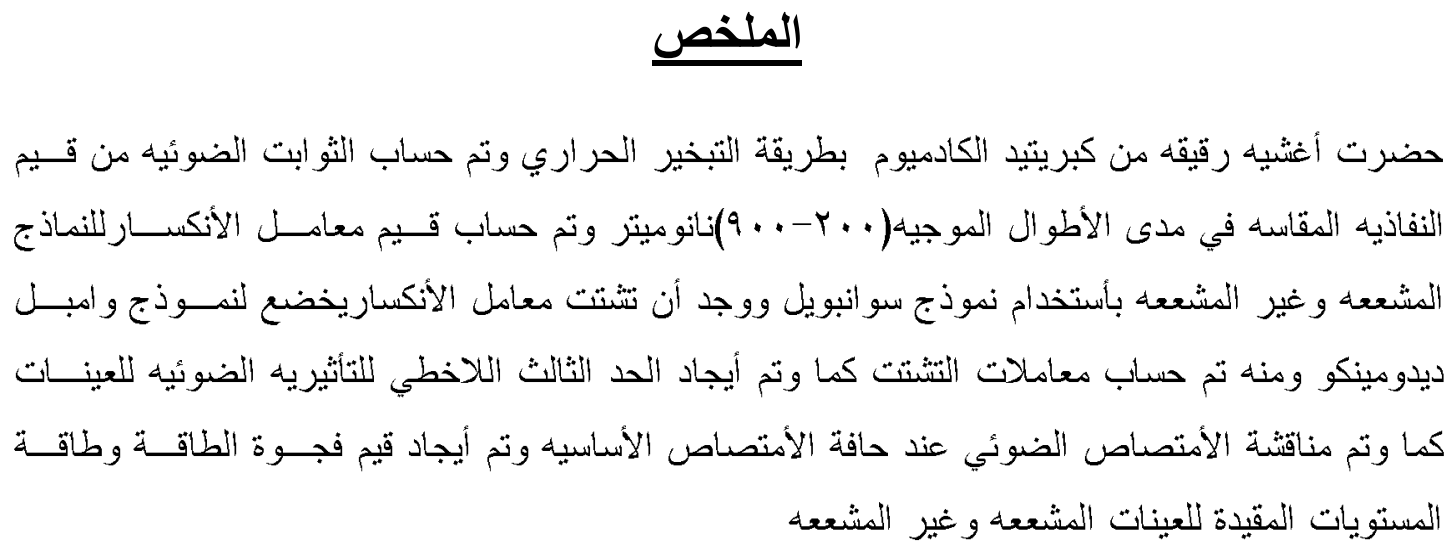

